\title{
Assessing the impact of late Pleistocene megafaunal extinctions on global vegetation and climate
}

\author{
M.-O. Brault ${ }^{1, *}$, L. A. Mysak ${ }^{1}$, H. D. Matthews ${ }^{2}$, and C. T. Simmons ${ }^{1}$ \\ ${ }^{1}$ Department of Atmospheric and Oceanic Sciences, McGill University, Montreal, Canada \\ ${ }^{2}$ Department of Geography, Planning and Environment, Concordia University, Montreal, Canada \\ * now at: Department of Geography, McGill University, Montreal, Canada
}

Correspondence to: M.-O. Brault (marc-olivier.brault@ mail.mcgill.ca)

Received: 6 November 2012 - Published in Clim. Past Discuss.: 21 January 2013

Revised: 19 June 2013 - Accepted: 20 June 2013 - Published: 2 August 2013

\begin{abstract}
The end of the Pleistocene was a turning point for the Earth system as climate gradually emerged from millennia of severe glaciation in the Northern Hemisphere. The deglacial climate change coincided with an unprecedented decline in many species of Pleistocene megafauna, including the near-total eradication of the woolly mammoth. Due to an herbivorous diet that presumably involved large-scale tree grazing, the mammoth extinction has been associated with the rapid expansion of dwarf deciduous trees in Siberia and Beringia, thus potentially contributing to the changing climate of the period. In this study, we use the University of Victoria Earth System Climate Model (UVic ESCM) to simulate the possible effects of these extinctions on climate during the latest deglacial period. We have explored various hypothetical scenarios of forest expansion in the northern high latitudes, quantifying the biogeophysical effects in terms of changes in surface albedo and air temperature. These scenarios include a Maximum Impact Scenario (MIS) which simulates the greatest possible post-extinction reforestation in the model, and sensitivity tests which investigate the timing of extinction, the fraction of trees grazed by mammoths, and the southern extent of mammoth habitats. We also show the results of a simulation with free atmospheric $\mathrm{CO}_{2}$-carbon cycle interactions. For the MIS, we obtained a surface albedo increase and global warming of 0.006 and $0.175^{\circ} \mathrm{C}$, respectively. Less extreme scenarios produced smaller global mean temperature changes, though local warming in some locations exceeded $0.3^{\circ} \mathrm{C}$ even in the more realistic extinction scenarios. In the free $\mathrm{CO}_{2}$ simulation, the biogeophysicalinduced warming was amplified by a biogeochemical effect, whereby the replacement of high-latitude tundra with shrub
\end{abstract}

forest led to a release of soil carbon to the atmosphere and a small atmospheric $\mathrm{CO}_{2}$ increase. Overall, our results suggest the potential for a small, though non-trivial, effect of megafaunal extinctions on Pleistocene climate.

\section{Introduction}

The final millennia of the Pleistocene epoch (which lasted until approximately $11.7 \mathrm{ky}$ ago) witnessed an important transitional period as the Earth system emerged from extended periods of Northern Hemisphere glaciation. This transition involved major changes in the land surface configuration as receding continental ice sheets gave way to the expansion of cold-adapted tundra vegetation, boreal shrub forest and evergreen needleleaf trees. In turn, the expansion of vegetation would have affected climate by modifying surface reflectivity and enhancing land-atmosphere $\mathrm{CO}_{2}$ exchange (Kabat et al., 2004). This could have either increased or slowed the rate of high-latitude warming and ice sheet erosion.

Also occurring during the late Pleistocene was one of the most significant terrestrial mass extinctions events of the Cenozoic (past 65 million years). In total, 97 of 150 genera of megafaunal mammals (defined as animals $>44 \mathrm{~kg}$ ) went extinct globally from about 50 thousand years ago until the end of the Pleistocene (Barnosky et al., 2004). These large terrestrial mammals have long been thought to play a central role in the maintenance of grasses over the expansion of trees in the Eurasian taiga due to a presumed herbivorous diet that would have involved large-scale tree grazing, in direct analogy to 
the behavior of present-day megafauna in the African savanna (Owen-Smith, 1987). For example, today a large elephant in South Africa consumes $300 \mathrm{~kg}$ of vegetation daily (U. Schutte, personal communication, 2012). Therefore, the extinction of the Pleistocene megafauna could have allowed an additional increase in high-latitude tree cover during the last deglaciation - and therefore a potential change in climate - that would not have occurred otherwise.

The exact cause of the Late Quaternary Extinctions is still subject to an active debate, with a lack of general consensus on the competing hypotheses of natural and anthropogenic causes (Koch and Barnosky, 2006; Prescott et al., 2012). The occasional presence of woolly mammoth (Mammuthus primigenius) remains in paleolithic sites has notably led to the development of various theories attributing the disappearance of the pre-historic mammals to over-hunting by humans (Alroy, 2001; Martin, 2005; Guthrie, 2006). Due to underwhelming evidence, many dismiss the "overkill" hypothesis in favor of natural climate change on the basis that the primitive tools used during the period combined with the woolly mammoth's thick layer of fat, skin and fur would have made effective hunting by humans unlikely (Grayson and Meltzer, 2002; Wroe et al., 2004).

Assuming humans did have the capacity to overhunt mammoth and significantly reduce their population, Doughty et al. (2010, hereafter DWF2010) hypothesized that the extinction of the woolly mammoth would have caused an expansion of high-latitude forest, leading to a decrease in surface albedo and a corresponding increase in surface temperatures. The assertion that megafaunal extinctions coincided with major regional changes in vegetation is supported by pollen records from a well-documented increase of Betula cover in Siberia and Beringia (Global Pollen Database), data from a collection of Alaskan mammoth fossils (Guthrie, 2006) and palaeological records (Gill et al., 2009). Based on this evidence, as well as the combined results of a predatorprey model and a global climate model, DWF2010 suggested that a human-driven mammoth extinction could constitute an early case of human-induced climate change and a potential pre-agricultural beginning for the Anthropocene.

In this paper we investigate the potential impact of megafaunal extinctions on deglacial climate change during the late Pleistocene by extending the modeling efforts of DWF2010 in three ways: (1) we examine the transient climate response to changes in vegetation cover; (2) we simulate this transient climate change using the multi-component University of Victoria Earth System Climate Model (UVic ESCM), considering boundary conditions relevant to the late Pleistocene (in terms of orbital parameters, ice sheets, and wind fields) as well as transient changes in ocean circulation and heat uptake; (3) we include a dynamic treatment of vegetation processes, where pre-extinction tree grazing by the woolly mammoths is characterized as a constraint on vegetation growth.
We first analyze results from a Maximum Impact Scenario (henceforth MIS) in which all trees and shrubs are assumed to be cleared in a vast area of the Northern Hemisphere, thus yielding the largest possible climate response resulting from the megafaunal extinctions in the UVic model. Atmospheric $\mathrm{CO}_{2}$ levels are prescribed in order to focus on biogeophysical effects in the climate response. Following this, we discuss a range of experiments testing model sensitivity to the tree grazing fraction, extent of mammoth habitats, and timing of extinction. Finally, we simulate free $\mathrm{CO}_{2}$-carbon cycle interactions in order to quantify the biogeochemical effects of vegetation changes.

This paper is structured as follows. In Sect. 2, we give a brief overview of the climatic impact of high latitude vegetation cover change. A short description of the UVic ESCM and the vegetation module are given in Sect. 3. Section 4 discusses the experimental design and the methodology used in this study. In Sect. 5 we give an analysis of the MIS results, while the results of all other experiments are briefly described in Sect. 6. Finally, some concluding remarks are given in Sect. 7.

\section{A review of climate-vegetation interaction at high latitudes}

The climate impact of forests at high latitudes is dominated by radiative effects that arise from vegetation-induced alterations of the surface albedo (Foley et al., 2003), due in large part to the contrast in surface reflectivity between the dark forest canopy and bare or grass-covered ground, which is greatly amplified by the presence of snow during the colder months. The impact on surface air temperature is further enhanced by a radiative feedback mechanism whereby the temperature anomaly brought about by the change in tree cover influences the onset of snow melt during the spring season, resulting in a higher temperature anomaly which enhances the initial change in tree cover. Additionally, moisture starvation at high latitudes limits the relative importance of heat losses through evapotranspiration, which dominates climatevegetation interactions in more temperate forest biomes.

The climatic role of high-latitude vegetation has been analyzed extensively with a variety of numerical models (see, for example, Brovkin et al., 2003; Crucifix et al., 2005). Otterman et al. (1984) were among the first to examine the impact of nontropical forest cover on climate, and suggested that boreal and temperate forests produce a warming effect on climate by reducing surface albedo. Thomas and Rowntree (1992) followed with a high-latitude deforestation experiment, and associated the resulting increase in wintertime and springtime surface albedo with a net decrease in surface air temperature and precipitation over the concerned regions, especially during the time of snow melt. Using an explicit scheme prescribing the complete removal of forests at northern high latitudes, Bonan et al. (1992) found that this cooling 
effect could be extended well beyond the deforested area due to sea ice-albedo feedbacks, and would tend to persist throughout the entire year owing to the oceanic thermal inertia. Subsequent studies with the same experimental setup (Bonan et al., 1995; Douville and Royer, 1997) confirmed these findings and hinted at significant climatic impacts of high-latitude tree cover changes in other parts of the globe, notably in terms of tropical monsoonal circulation. Overall, results from global-scale modeling (Claussen et al., 2001; Snyder et al., 2004; Fraedrich et al., 2005; Gibbard et al., 2005; Bala et al., 2007; Brovkin et al., 2009; Bathiany et al., 2010) suggest that radiative effects at mid- to high latitudes drive climate-biosphere interactions. More explicitly, the impact of surface albedo change outweighs that of all other biogeophysical effects associated with land cover change (Davin and de Noblet-Ducoudré, 2010).

Climate-vegetation interactions have also been investigated with higher resolution regional climate models, with somewhat differing results. For example, a simulation of deforestation in Europe (Chalita and Le Treut, 1994) yielded a wet spring followed by a dry summer, a seasonal spread of precipitation which is inconsistent with global modeling experiments. These results were further confirmed by another regional climate model study in Europe (Heck et al., 2001). Focusing on the eastern half of Russia, Notaro and Liu (2008) found that local deforestation led to an extended snow cover period and increased atmospheric stability, strengthening the Siberian High and thus decreasing convective precipitation in the region. These findings thus hint at a significant impact of high-latitude forests on regional climate patterns.

Finally, it is necessary to consider the importance of vegetation in regulating atmospheric carbon dioxide levels and maintaining the carbon cycle. This is achieved through carbon sequestration by photosynthesis, as well as carbon exchanges with the soil layer. The reverse is also true, as vegetation can also be affected by changes in atmospheric carbon dioxide - not only from its direct impact on global surface temperatures, but also due to the central role of the $\mathrm{CO}_{2}$ molecule in the chemical reactions that define plant life (Prentice et al., 1991). For example, a known impact of elevated atmospheric $\mathrm{CO}_{2}$ levels is to cause physiological changes such as a reduction of plant stomatal conductance, which limits moisture exchanges between the plant and its environment (Foley et al., 1996). Therefore, the role of vegetation within the carbon cycle is of considerable relevance to any investigation of $\mathrm{CO}_{2}$ variations and climate change.

\section{Model description}

The model used in this study is version 2.9 of the University of Victoria Earth System Climate Model (henceforth UVic ESCM, or UVic model), an intermediate complexity coupled atmosphere/ocean/sea-ice model with integrated land surface and vegetation schemes (Weaver et al., 2001). The ocean component of the model is version 2.2 of the GFDL Modular Ocean Model (MOM), a three-dimensional ocean general circulation model with 19 unequally spaced vertical levels (Pacanowski, 1995). The atmosphere is a vertically integrated energy-moisture balance model (EMBM) first introduced and coupled to the MOM by Fanning and Weaver (1996), and simplified in Weaver et al. (2001). Moisture transport is driven by diffusion and by vertically integrated atmospheric winds specified from NCEP reanalysis data. A dynamic wind feedback parameterization based on variations in sea surface temperatures is included to account for wind perturbations in past climate simulations. Sea ice is calculated with a standard model involving two-category (sea ice, open water) thermodynamics and elastic-viscous plastic dynamics, with further options available for a more sophisticated representation of sea-ice thermodynamics and ice thickness distributions (Bitz et al., 2001). The spatial coverage and height of ice sheets is prescribed based on data from the model ICE-4G (Peltier, 1994). Finally, the land-sea configuration used in all sub-components operates in a global spatial domain with a spherical grid resolution of $3.6^{\circ}$ (zonal) by $1.8^{\circ}$ (meridional), which is comparable to most coupled coarse-resolution AOGCMs.

In the current version of the UVic ESCM land surface properties (surface temperature, soil moisture content and temperature, snow cover) and soil carbon content are computed with a single $(1 \mathrm{~m})$ soil layer version of the Meteorological Office Surface Exchange Scheme version 2 (MOSES2 ), which is driven by biomass input and microbial respiration (Cox et al., 1999). MOSES-2 includes an interactive representation of plant photosynthesis and conductance, and a parameterization of evapotranspiration as a function of canopy resistance. Newer versions of the model include an improved radiative transfer scheme, the addition of sulfates and aerosols as potential climate forcings (Matthews et al., 2004), the introduction of a dynamic vegetation model (Meissner et al., 2003) (see below), and a coupling of the latter's terrestrial carbon cycle with the ocean's inorganic carbon cycle (Matthews et al., 2005). More recently, modules for ocean biogeochemistry (Schmittner et al., 2008) and ocean sediment deposition and dissolution (Eby et al., 2009) have also been incorporated into the UVic ESCM.

The terrestrial biosphere is represented with the vegetation module "TRIFFID" (Top-down Representation of Interactive Foliage and Flora Including Dynamics), a dynamic global vegetation model developed at the Hadley Centre for use in climate-carbon cycle simulations (Cox, 2001), and adapted to the UVic model by Meissner et al. (2003). TRIFFID describes the state of the terrestrial biosphere in terms of soil carbon (one-layer) and vegetation distribution, which is expressed in terms of the structure and coverage of five plant functional types (PFT): broadleaf trees, needleleaf trees, C3 and $\mathrm{C} 4$ grasses (mainly distinguished by their photosynthesis patterns; $\mathrm{C} 4$ is found almost exclusively in the tropics), 
and shrubs (defined as trees whose maturity height does not exceed $2 \mathrm{~m}$ ). Plant distribution and soil carbon levels are updated according to a "carbon balance" approach, which is based on primary productivity and land-atmosphere carbon fluxes supplied by MOSES-2. Areal coverage is determined by the net available carbon and interspecies competition, which is modeled using a Lotka-Volterra predator-prey relationship. In particular, the plant dominance hierarchy heavily emphasizes the role of height in the competition for areal surface, which induces a heavy bias towards taller species. The model also accounts for bud-burst, leaf-drop and large-scale vegetation disturbances that increase the soil carbon content.

\section{Experimental setup}

In this study we examined the climate impacts of the megafaunal (i.e., mammoth) extinction, which is represented as an increase in high-latitude tree cover, following the hypothesis formulated in DWF2010. In order to simulate an additional increase in tree cover not caused by existing processes in the model, we define a "mammoth area" which is initially deforested, partially or totally (physically, this approach can be justified by arguing the grazing of trees by terrestrial fauna is not accounted for in the current version of the model), and where trees and shrubs are only allowed to grow back subsequent to the pre-defined timing of mammoth extinction. The climatic impacts of forest recovery in the "mammoth area" can then be used to directly quantify the biogeophysical and/or biogeochemical effects associated with the megafaunal extinction.

In the context of the PFT approach in TRIFFID, the experimental setup limits the growth of trees and shrubs in favor of C3 and C4 grasses over the specified "mammoth area", much in the same way as one would account for agriculture in the distribution of present-day vegetation. Once in equilibrium with most other model components (preliminary tests with the UVic ESCM revealed that $500 \mathrm{yr}$ of model simulation are sufficient to reach an approximate steady state when perturbing an already spun-up model), this constraint on highlatitude tree growth is then removed over a single time step, at the pre-defined timing of extinction. The mammoth extinction is taken to be "instantaneous" for the sake of simplicity, and in order to minimize the time required for vegetation to reach its quasi-equilibrium state. Due to the strong dominance of tree and shrub PFT in the competition scheme, the recovery happens over the span of a few hundred years only. In order to isolate the climate response due to biogeophysical effects only, we compare the output of the extinction scenario EXT with a control run CTL, for which the constraint on trees and shrubs is maintained for the duration of the simulation (i.e., no mammoth extinction). Unless otherwise indicated, all figures presented below represent the departure between a simulation EXT and its corresponding CTL run.
Most of the model simulations were carried out using a pre-defined time series of atmospheric $\mathrm{CO}_{2}$ obtained from Vostok ice cores (Petit et al., 1999) in order to eliminate the possible effects of vegetation cover changes on carbon dioxide radiative forcing. The initial conditions for these simulations were obtained from the experiments presented in Simmons et al. (2012). These experiments were, in turn, derived from a spin-up for $21000 \mathrm{BC}$ (23000 BP) run for 10000 model years with Last Glacial Maximum $(\sim 19000 \mathrm{BC})$ ice cover (ICE4G), orbital forcing and atmospheric $\mathrm{CO}_{2}$ fixed for $21000 \mathrm{BC}$. This spin-up was then used as the basis for transient simulations from $21000 \mathrm{BC}$ to $2000 \mathrm{AD}$. The initial conditions for the present study were then derived from one such transient simulation using time-dependent orbital forcing, prescribed land ice (ICE4G) and prescribed $\mathrm{CO}_{2}$ (Vostok) at the start dates (ranging from $15000 \mathrm{BC}$ to $10000 \mathrm{BC}$ ) for the simulations described in this paper.

\section{The Maximum Impact Scenario (MIS)}

In this experiment we define the "mammoth area" as any land grid cell located north of the $30^{\circ} \mathrm{N}$ latitude, the approximate southernmost limit of boreal forests in the model's Northern Hemisphere during the late Pleistocene. Most of the vegetation in North America is constrained between $30^{\circ} \mathrm{N}$ and $45^{\circ} \mathrm{N}$ due to the overwhelming presence of the Laurentide ice sheet. Within the "mammoth area" the effective preextinction tree and shrub fraction are set to zero (i.e., full deforestation). The timing of extinction is set at the model year $12000 \mathrm{BC}$ (14 ky BP), as suggested by the evidence from various burial sites (Guthrie, 2006). In the following sub-sections, we will examine the evolution of surface albedo and air temperature over the following $500 \mathrm{yr}$ (from $14 \mathrm{ky} \mathrm{BP}$ to $13.5 \mathrm{ky} \mathrm{BP}$ ). We emphasize that the MIS does not represent a realistic scenario in terms of the megafaunal extinction; rather, it models the greatest conceivable influence of megafauna on late Pleistocene climate in the UVic model. Other more realistic experiments will be discussed later.

\subsection{Vegetation and surface albedo}

The change in the fractions of trees, grasses and shrubs over the mammoth area (Fig. 1a) displays two interesting features. First, most of the vegetation distribution change occurs within the first $100 \mathrm{yr}$ of the simulated mammoth extinction. The expansion of the boreal forest is likely hastened by the height-based plant dominance hierarchy in the TRIFFID competition scheme, which emphasizes the growth and expansion of tree and shrub types over grass. Second, the transition involves mostly a change from grasses to shrubs, with needleleaf trees only appearing in Europe and southwestern North America towards the end of the simulation period. This does not contradict the conclusions of DWF2010: based on physical and physiological properties, the PFT best 


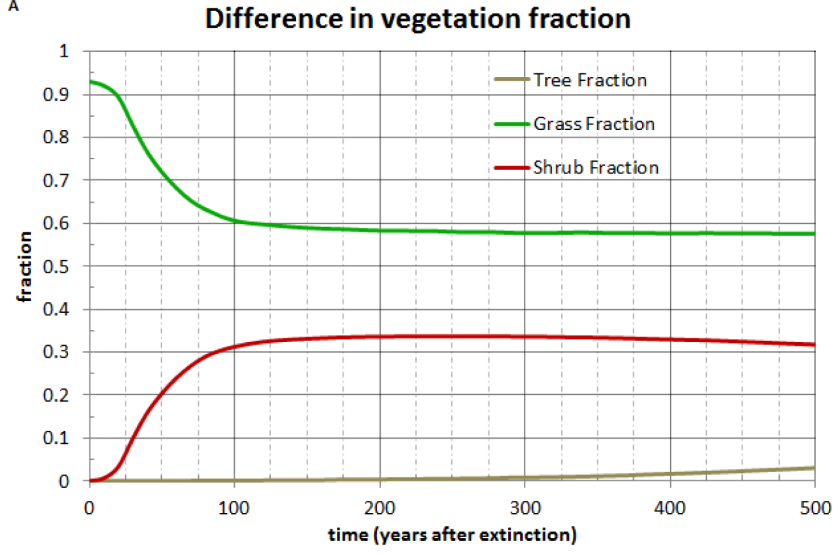

B

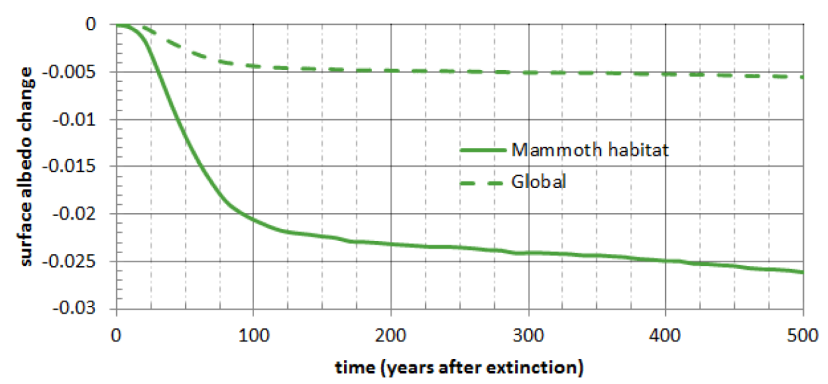

c

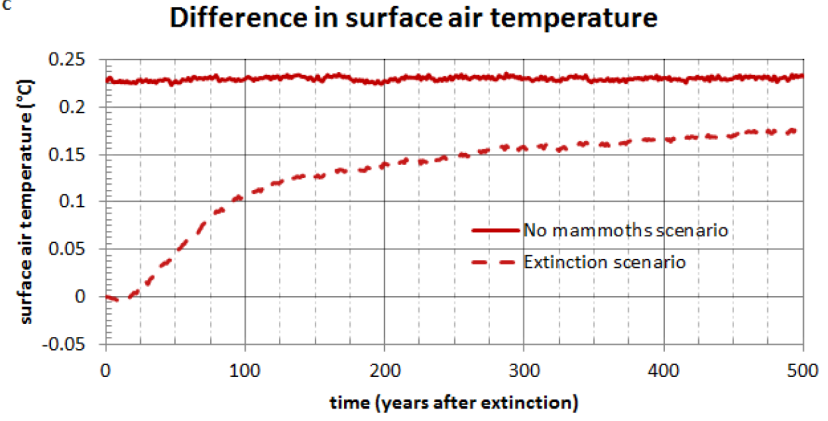

Fig. 1. Results of the MIS (maximum impact scenario - all trees north of $30^{\circ} \mathrm{N}$ removed by the mammoths, so that their extinction results in the largest possible reforestation), plotted as time series of the first $500 \mathrm{yr}$ after extinction. To produce each curve we subtract the control run (CTL - model tuned with the mammoths' impact on vegetation, but the mammoths do not go extinct) from the extinction run (EXT - same as CTL, but the mammoths go extinct at year 0 of the simulation); the only exception is the solid line in (c), in which CTL is subtracted from the background simulation (no mammoths). The panels display differences in (a) the vegetation fraction for every main vegetation type, averaged over the mammoth area; (b) the surface albedo, averaged over the globe (dashed line) and over the mammoth area (solid line); and (c) the globally-averaged temperature for the "extinction" run (dashed line) and the "no mammoths" background simulation (solid line).

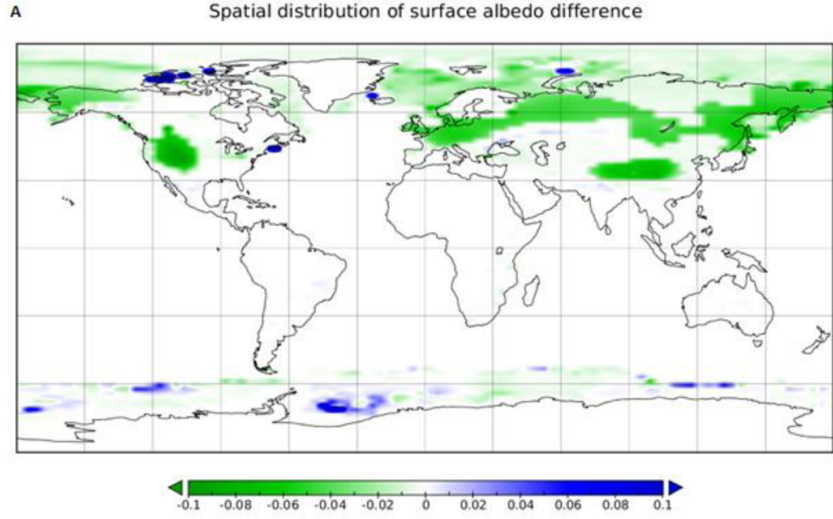

B

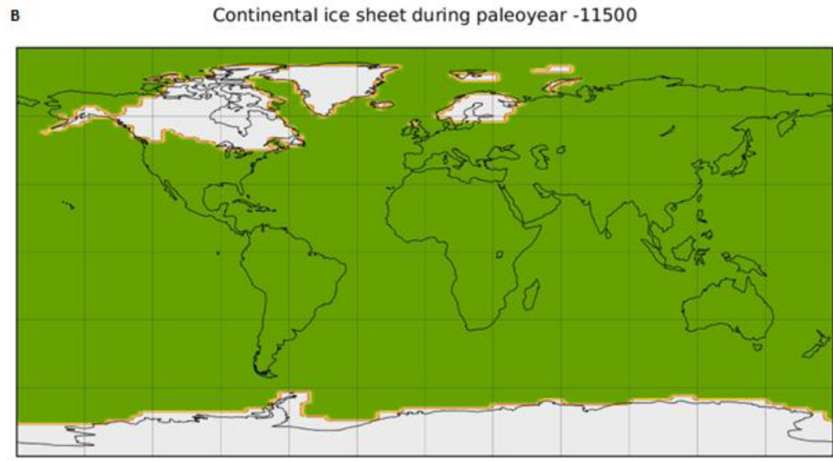

Fig. 2. Spatial distribution of (a) difference in surface albedo (EXTCTL) averaged over the 500th year of the climate model simulation and (b) prescribed ice sheets during the 500th year.

representing the Betula species would likely be the shrub type in TRIFFID.

The time evolution of surface albedo (Fig. 1b) is found to closely follow the change in vegetation. After $500 \mathrm{yr}$ of climate model simulations, the change in surface albedo due to biogeophysical effects alone amounts to -0.026 locally (mammoth area), and approximately -0.006 globally. The spatial distribution of this increase in albedo is displayed in Fig. 2a. A large area of North America is unavailable for tree growth due to continental ice sheets (see Fig. 2b). Furthermore, in the model several places in Asia are either too cold (in most of Siberia) or too dry (all of southern Asia, with the exception of the Himalayan mountain range) to support the growth of trees and shrubs. This limits the extent of shrub forests to a longitudinal band of land stretching from Europe to the Pacific coast and western Alaska, as well as several high-elevation locations (the Himalayas in Asia and Rocky Mountains in North America).

Since shrubs are very similar to grasses in terms of snowfree surface reflectivity, most of the observed albedo decrease is caused by a difference in snow-covered canopy albedo ( 0.6 for grasses versus 0.4 for shrubs). As would be expected, the departure in surface albedo, largest at the reforested latitudes, all but vanishes during summer and early fall when the ground becomes snow free (see Fig. 3). The postglacial 


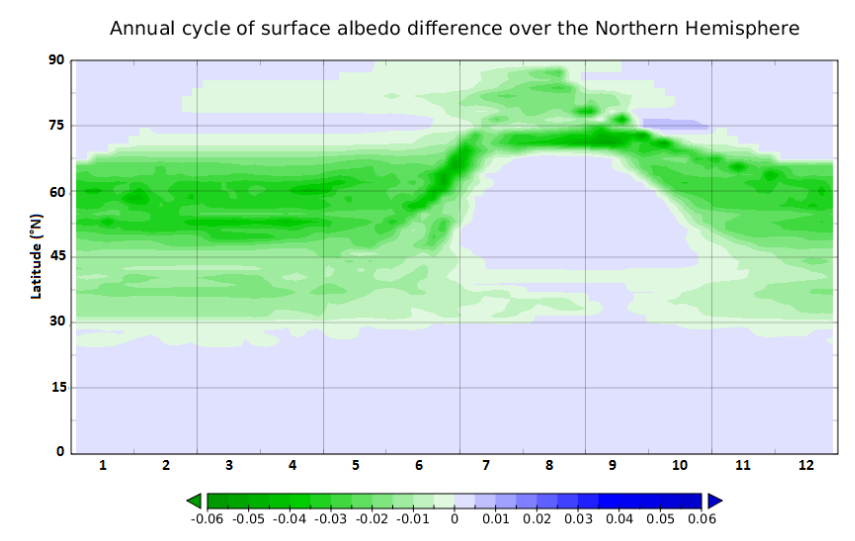

Fig. 3. Zonally-averaged annual cycle of the difference in surface albedo (EXT-CTL) over the Northern Hemisphere during the 500th year of the climate model simulation. On the abscissa, months are displayed from January to December according to their numerical order.

climate regime in the Northern Hemisphere results in a much later spring snowmelt compared to the present day, as characterized by albedo anomalies that persist until mid-June at these latitudes. This contrasts with simulations of presentday climate (Thomas and Rowntree, 1992; Chalita and Le Treut, 1994), in which the boundary conditions hasten the melting season by several months compared to the case for the late Pleistocene. According to Fig. 3, the (negative) surface albedo anomaly in the reforested latitudes is largest at the end of the spring season. An analysis of seasonal SAT anomalies (see Fig. 5 below) and land surface temperature anomalies (not shown) also reveals that during the same time period this region is much warmer in the reforestation run (EXT) than in the control run (CTL). We interpret these findings as a possible indication that the darker canopy of dwarf trees leads to an earlier spring, and snow melt is hastened by up to a few weeks due to the snow-albedo feedback.

\subsection{Temperature}

The simulated change in temperature is displayed in the form of a globally averaged time series of SAT anomalies (Fig. 1c). The temperature and surface albedo trends are well-correlated, and $500 \mathrm{yr}$ into the simulation the temperature anomaly is approximately $0.175^{\circ} \mathrm{C}$ globally and $0.42^{\circ} \mathrm{C}$ over the mammoth area. The rapid northward expansion of shrub forest causes a sharp warming during the first $100 \mathrm{yr}$ of the simulation. A weaker temperature increase continues into the rest of the simulation, likely a result of receding ice sheets and the increased availability of land surface towards the expansion of non-grass vegetation. This increases the contrast between the EXT and CTL simulations, since in the latter the tree and shrub PFTs are not allowed to grow back in the mammoth area. Because the postglacial warming period extends well into the Holocene, it is possible that the resulting temperature departure between the two simulations would continue to slowly increase well beyond the $500 \mathrm{yr}$ of this simulation, as evidenced by the closing of the gap between the "extinction" run and the background simulation (solid line in Fig. 1c).

The temperature change obtained at the end of the MIS is several times larger than the change presented in the results of DWF2010, who obtained a $0.026^{\circ} \mathrm{C}$ warming with a $6 \%$ increase in Siberian tree cover. This discrepancy is to be expected, however, given that DWF2010 simulate a $6 \%$ increase in tree cover over an area much smaller than the one used in this study; it is therefore difficult to establish the validity of our results based on a direct comparison with their results. Nevertheless, our results reinforce the idea that a postglacial expansion of high-latitude vegetation - possibly caused by the extinction of the Pleistocene megafauna contributed to global warming during the late Pleistocene.

In terms of the global impact of high-latitude reforestation, we produce results that are similar to other presentday afforestation experiments, which were carried out to investigate the climate change mitigation potential of forest regrowth (e.g. Betts, 2000; Arora and Montenegro, 2011). While these studies find a possible cooling effect of afforestation due to the increase in vegetation carbon sequestration, both point out the importance of albedo changes at high latitudes, which either partially or completely counterbalance the impact of decreased $\mathrm{CO}_{2}$ levels. It is also likely that the snow-albedo feedback mechanism is enhanced during the deglaciation because of the delayed melting season (as well as a favorable orbital configuration), producing a greater impact than would be obtained with modern-day boundary conditions.

In general, there is good correlation between the spatial patterns of temperature (Fig. 4) and albedo (Fig. 2a), with maximum temperature anomalies located in the reforested areas (negative anomalies in Fig. 2a). Also, the seasonal cycle for the temperature anomalies (see Fig. 5) is very consistent with results from earlier studies (Thomas and Rowntree, 1992; Bonan et al., 1992; Douville and Royer, 1996); but due to the cooler glacial climate, the peak anomalies in our study tend to occur later. However, the spatial temperature response is not fully linear with respect to vegetation and albedo changes; the rest of this section discusses two of the most notable features in the spatial pattern.

The largest temperature departure $\left(\sim 0.6^{\circ} \mathrm{C}\right)$ can be found in extreme northeastern Asia, despite a change in surface albedo comparable to that in central Europe, where only half as much warming is observed (see Fig. 4). We conjecture that the temperature response is enhanced by a particularly longlasting snow-albedo feedback mechanism due to its northern location, promoting warmer temperatures during most of the year. Warmer springtime temperatures hasten the snowpack melt by up to a few weeks, significantly reducing surface albedo during the late spring and early summer, the time of year when temperature is most sensitive to surface 


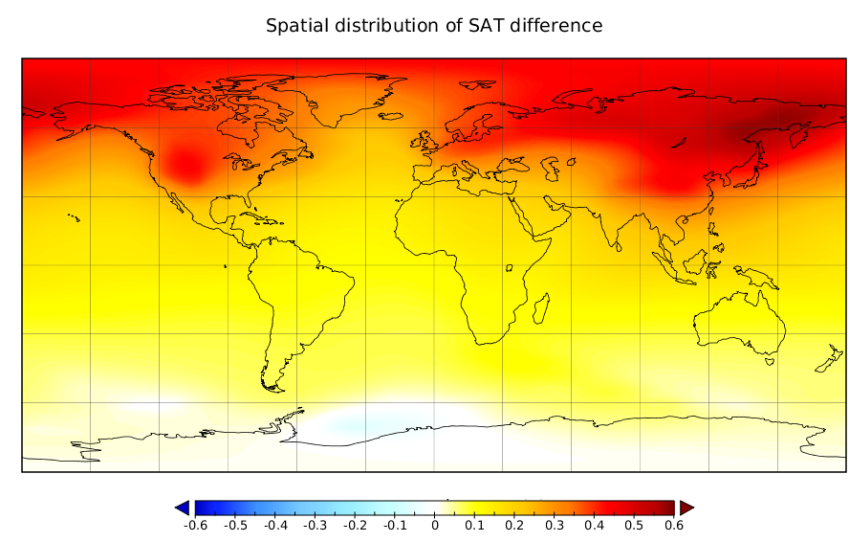

Fig. 4. Annually-averaged spatial distribution of the difference in temperature (EXT-CTL) averaged over the 500th year of the climate model simulation.

reflectivity. It should also be noted that the temperature response in Europe is likely smaller due to its proximity to the North Atlantic Ocean's moderating influence.

The Weddell Sea, off the Antarctic shoreline, is the only area where a negative temperature anomaly is observed (see Fig. 4) as a result of biogeophysical effects in the Northern Hemisphere. An analysis of the modeled ${ }^{14} \mathrm{C}$ content of the deep waters in the Weddell Sea at the end of the simulation (Fig. 6) reveals a strengthening vertical gradient of $\delta^{14} \mathrm{C}$ in the bottom waters, which is indicative of reduced deep water formation in the Southern Ocean and reduced ocean-to-atmosphere heat transfer. These cooler, more stratified surface waters can also lead to increased sea ice formation, triggering a local sea ice-albedo feedback with negative impacts on air temperature (and providing a possible explanation to the positive albedo anomalies near the coast of Antarctica as seen in Fig. 2a). These findings suggest that warm SST anomalies in the North Atlantic trigger a change in oceanic circulation which inhibits deep water formation in the Southern Ocean, explaining why this region could experience a slight cooling despite a major warming in the Northern Hemisphere.

\section{Results of other experiments}

\subsection{Intermediate-impact scenarios and sensitivity tests}

In this section we investigate the role of megafaunal diet, habitat range, and timing of extinction by performing a set of sensitivity studies that explore more realistic scenarios of mammoth extinction.

The experiments discussed here focus on the impacts of three independent characteristics: the rate of tree clearing (also referred to as "herbivory"), the spatial extent of mammoth influence on vegetation (i.e., the "mammoth area"), and the timing of extinction. We represent the rate of tree clearing

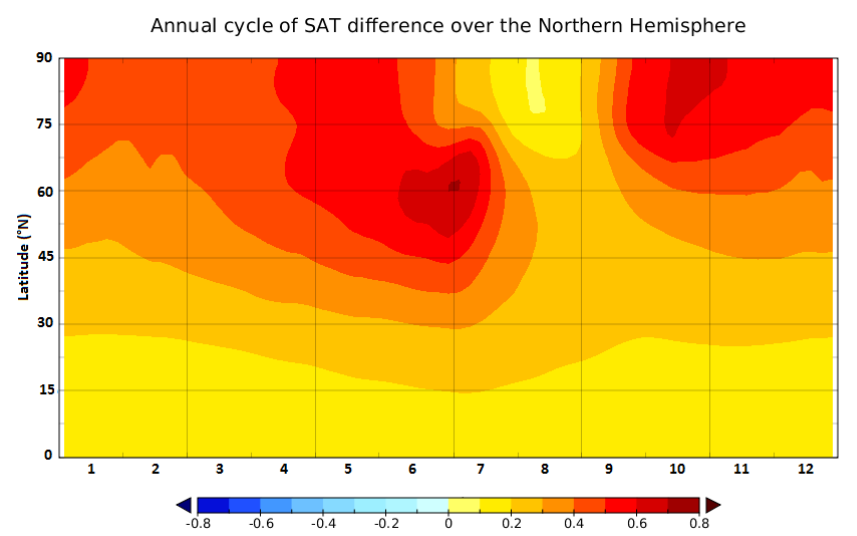

Fig. 5. Zonally-averaged annual cycle of the difference in temperature (EXT-CTL) over the Northern Hemisphere, during the 500th of the climate model simulation. On the abscissa, months are displayed from January to December according to their numerical order.

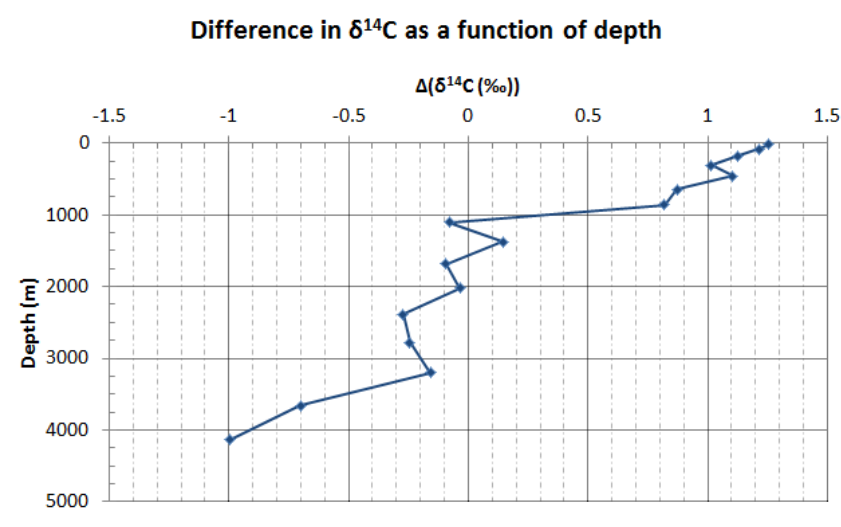

Fig. 6. Variations in $\delta^{14} \mathrm{C}$ anomaly as a function of depth in the Weddell Sea (region of negative temperature anomaly in Fig. 4), averaged over the 500th year of the climate model simulation.

as a constraint on the growth of tree and shrub PFT, limiting (but not suppressing) their maximum fractional cover over the mammoth area. Furthermore, the size of the mammoth area is set according to a latitudinal southernmost boundary. While perhaps crude representations of mammoth herbivory and habitat, we argue that they are reasonable given the sparse paleodata available on the eating habits and the spatial distribution of megafaunal species during the late Pleistocene. Finally, in order to explore different times of extinction, we launch the simulations with boundary conditions selected for various stages of deglacial climate change, producing a different context of natural climate variability.

Results from these sensitivity studies are summarized in Fig. 7. The details of each experiment are presented in Table 1 and compared with the MIS; two simulations are displayed for each of the three characteristics discussed above.

In general, model results from the sensitivity tests agree with our intuition. Decreased herbivory and tree grazing 
Table 1. List of sensitivity tests, performed for the three characteristics selected for this study: year of extinction, tree clearance fraction, and southern extent of mammoth habitat. For the sake of comparison, parameterizations for the MIS are shown in the first line.

\begin{tabular}{lrrr}
\hline Description & $\begin{array}{r}\text { Year of } \\
\text { extinction }\end{array}$ & $\begin{array}{r}\text { Fraction of } \\
\text { trees cleared }\end{array}$ & $\begin{array}{r}\text { Southern extent } \\
\text { of habitat }\end{array}$ \\
\hline Maximum Impact Scenario & -12000 & 1.00 & $30^{\circ} \mathrm{N}$ \\
$30 \%$ Reduced Herbivory & -12000 & 0.70 & $30^{\circ} \mathrm{N}$ \\
$60 \%$ Reduced Herbivory & -12000 & 0.40 & $30^{\circ} \mathrm{N}$ \\
$45^{\circ} \mathrm{N}$ Habitat Limit & -12000 & 1.00 & $45^{\circ} \mathrm{N}$ \\
$60^{\circ} \mathrm{N}$ Habitat Limit & -12000 & 1.00 & $60^{\circ} \mathrm{N}$ \\
Later Extinction & -10000 & 1.00 & $30^{\circ} \mathrm{N}$ \\
Earlier Extinction & -15000 & 1.00 & $30^{\circ} \mathrm{N}$ \\
\hline
\end{tabular}

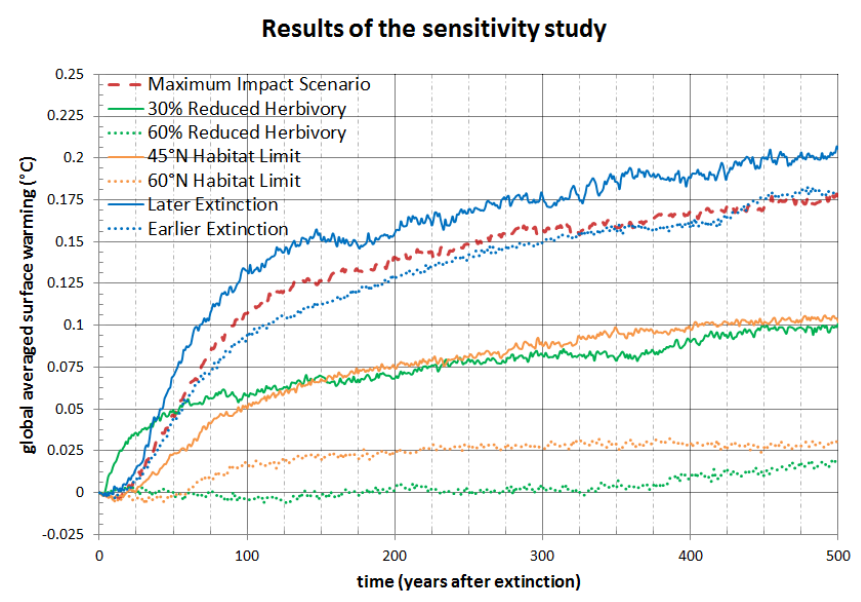

Fig. 7. Results of the sensitivity tests, presented here as time series of the difference in temperature (EXT-CTL) for various extinction scenarios. The MIS curve (same as dotted line in Fig. 1c) is shown in red for the sake of comparison.

effectively decreases the change in albedo - and temperature - when compared to the MIS. Interestingly, a $30 \%$ decrease in tree grazing approximately halves the impact on global temperature, while a $60 \%$ reduction has an insignificant impact on temperature. All of the main features discussed in Sect. 5 - the geographical distribution of anomalies, the large eastern Siberia warming and the Southern Ocean cooling are reproduced in these experiments, with proportionately smaller values.

It is also fairly straightforward to interpret results from sensitivity to the size and geographical boundaries of the mammoth area. When reducing the size of mammoth habitat, all potential input from excluded areas (in terms of radiative effects) effectively vanishes. Displacing the southern boundary to $45^{\circ} \mathrm{N}$ reduces the impact by about half, while moving it to $60^{\circ} \mathrm{N}$ negates biogeophysical effects, as there are very few ice-free locations north of this boundary that can support tree and shrub vegetation. The model output displays broad similarities with the MIS, reproducing the temperature anomalies in eastern Siberia and in the Southern Ocean.
Sensitivity to the timing of extinction is heavily dependent on boundary conditions, especially in terms of continental ice sheet coverage. An earlier extinction by some $3000 \mathrm{yr}$ (15 ky BP) yields a global temperature anomaly comparable to that obtained in the MIS (see Fig. 7); however, no cold pocket is found in the Weddell Sea (not shown). It is possible that slightly lower global temperatures during that period (and therefore a lower freshwater flux into the North Atlantic Ocean) prevented a weakening of the thermohaline circulation, thus negating the cooling effect in the Southern Ocean. A later extinction by some $2000 \mathrm{yr}$ (10 ky BP) results in further enhanced SAT anomalies compared to the MIS (see Fig. 7). The spatial distribution of temperature anomalies is slightly different at the northern high latitudes due to a moderately large fraction of the continental ice sheets vanishing between $12 \mathrm{ky} \mathrm{BP}$ and $10 \mathrm{ky}$ BP (as prescribed in the UVic ESCM), opening up more land area for the northward expansion of vegetation.

\subsection{Biogeophysical vs. biogeochemical effects: results from a "free $\mathrm{CO}_{2}$ " experiment}

In this section we investigate the impacts of climate-carbon cycle interactions. More specifically, we allow $\mathrm{CO}_{2}$ levels to fluctuate based on land cover changes in an attempt to quantify the biogeochemical effects of vegetation cover changes. For the sake of consistency, we use the experimental setup used in the MIS.

As shown in Fig. 8a, radiative and carbon-cycle effects appear to enhance each other, resulting in a combined warming that nearly doubles that from biogeophysical effects alone. This can be mostly attributed to an increase in atmospheric $\mathrm{CO}_{2}$ levels by about 15 ppm during the first 150 postextinction years (see Fig. 8b), which is followed by a gradual recovery as the additional atmospheric carbon is taken up by other carbon reservoirs (i.e., the ocean). As a result, the temperature anomaly for the 500 climate model years of the simulation is overwhelmingly positive.

An analysis of carbon fluxes above the land surface reveals that the release of $\mathrm{CO}_{2}$ to the atmosphere is closely related to the vegetation change. In the vegetation model, terrestrial carbon storage is determined by the balance of primary productivity (leading to carbon uptake) and decomposition (leading to release of soil carbon to the atmosphere). A transition from grass PFTs to shrubs leads to an increase in vegetation carbon over time; however shrubs also sequester less carbon in the soil pool compared to C3 grasses. Consequently, the replacement of grasses with shrubs leads to a substantial release of soil carbon to the atmosphere as the soil carbon pool adjusts to the reduced inputs from the new vegetation cover. This decrease in soil carbon content (Fig. 8c) is larger than the corresponding increase in vegetation carbon (Fig. 8d), leading to a net loss of terrestrial carbon to the atmosphere. 


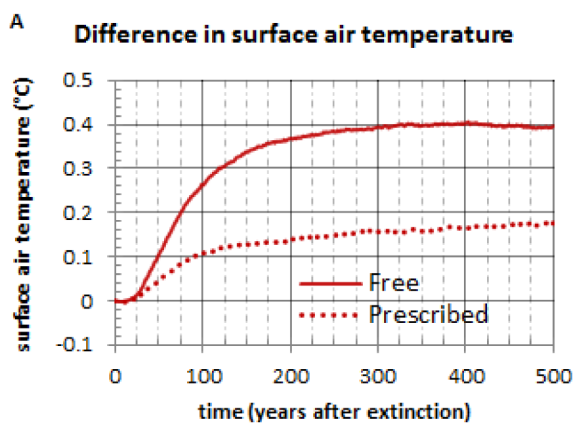

C

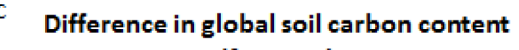
(free-CTL)

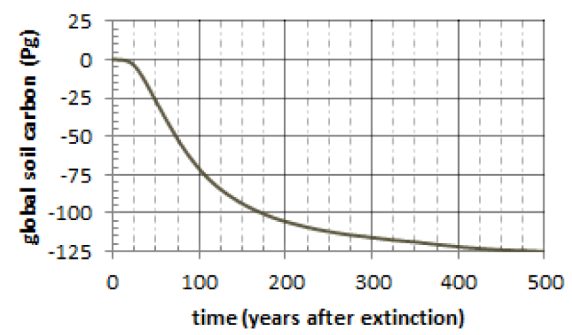

B
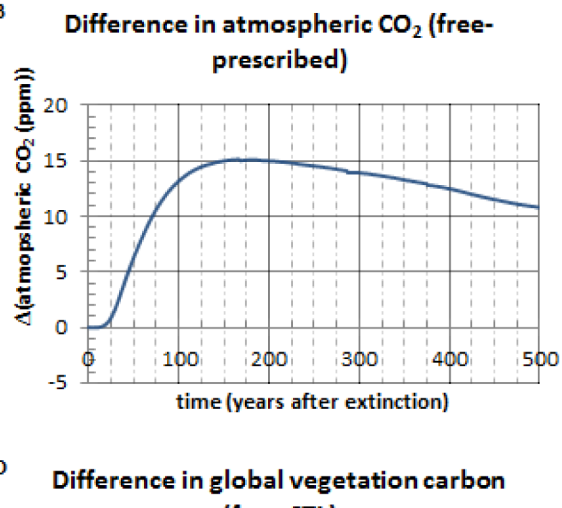
(free-CTL)

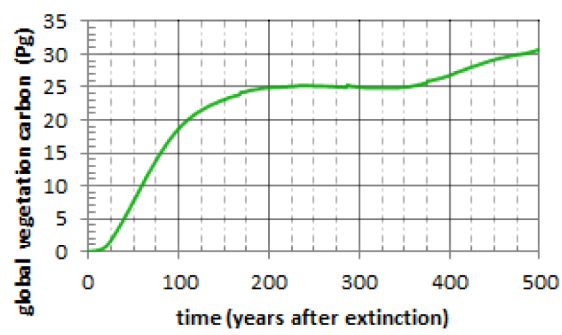

Fig. 8. A selection of results from the "free $\mathrm{CO}_{2}$ " experiment. Displayed are (a) the difference in temperature (EXT-CTL) for the free and prescribed $\mathrm{CO}_{2}$ experiments (dotted line is the same as dotted line in Fig. 1c); (b) the difference in atmospheric $\mathrm{CO}_{2}$ between the two simulations; (c) the difference in total soil carbon and (d) the difference in total vegetation carbon resulting from the vegetation change.

It is difficult at this point to determine whether the carbon cycle response to the vegetation change in this model reflects a potential real-world effect. It is consistent, however, with previous studies which have shown the potential for significant soil carbon losses associated with vegetation transitions (e.g. Meissner et al., 2003). In addition, there is evidence that real-world natural grasslands sequester large amounts of soil carbon (e.g. De Deyn et al., 2008), and so it is plausible that the replacement of grass-dominated ecosystems with shrub land may have led to an initial increase in atmospheric $\mathrm{CO}_{2}$ as shown in our results.

\section{Conclusions}

This paper investigates biogeophysical and biogeochemical effects of faunal and floral changes on climate in the context of the Late Quaternary Extinctions and provides a quantitative assessment of feedback mechanisms involving surface albedo and temperature. To this end, we established an experimental strategy using a land-cover perturbation to represent the stress on high-latitude vegetation caused by megafaunal herbivory. This setup was then used to explore several hypothetical cases of the mammoth extinction, including a catastrophic Maximum Impact Scenario (MIS) and a collection of more realistic variations of the former.

For the MIS we found the change in temperature following the mammoth extinction to be dominated by radiative effects, with an estimated surface warming of $0.175^{\circ} \mathrm{C}$ globally and $0.420^{\circ} \mathrm{C}$ over the mammoth area. Most of the warming could be linked to changes in vegetation, either as a direct consequence of reforestation or as a result of global warming through the expansion of hospitable terrain for trees and shrubs. As outlined in previous studies (Thomas and Rowntree, 1992; Bonan et al., 1992; Douville and Royer, 1996) the warming was found to be most pronounced in winter and spring, during which the albedo difference is greatest between the snow-covered ground and the dark forest canopy. Although positive temperature anomalies dominated worldwide, cooling was observed in the Weddell Sea, a likely indicator of reduced deep water formation in the Southern Ocean.

In general, the range of sensitivity studies produced fairly intuitive results. The amplitude of the temperature response displayed a monotonic, albeit slightly nonlinear, dependency on both the size of mammoth habitat as well as the tree clearance ratio. Displacing the timing of extinction by a few thousand years did not appear to yield a significant difference with the MIS. However, a simulation of free carbon exchanges with the atmosphere produced unexpected results, as the reforestation was found to coincide with a significant input of $\mathrm{CO}_{2}$ to the atmosphere, seemingly originating from the land surface reservoir.

Due to a strong height-based plant dominance hierarchy in TRIFFID, shrub types had mostly recovered their equilibrium distribution within $100 \mathrm{yr}$ of the mammoth extinction, 
perhaps too quickly for a natural reforestation. As expected due to the nature of our experiment, most of the albedo and temperature response was found to happen during this initial $100 \mathrm{yr}$ regrowth. The remnants of LGM ice sheets were found to significantly influence the model output, especially in North America, where potential reforestation was hampered by the Laurentide ice sheet. Our results also suggest that late Pleistocene boundary conditions led to a much later spring in the northern high latitudes, where spring snowmelt could be delayed by as much as several months compared to the present day.

In order to elaborate on the results obtained in this paper, it would be of interest to carry out simulations of the megafaunal extinctions with a more detailed representation of atmospheric dynamics. Such studies could also integrate realistic tree-mammoth scenarios with a predator-prey model, something that was disregarded in the present study for the sake of simplicity. Other mechanisms and processes that could be investigated include water vapor feedback (Swann et al., 2010) and nutrient availability following the extinction (Zimov et al., 2009). Finally, we recommend a more thorough investigation of land surface processes and large-scale vegetation changes (e.g., explore different boundary conditions and other dynamic global vegetation models), as most of the more counterintuitive results obtained here originated from an abrupt change in the dominant PFT.

Acknowledgements. This paper is based on a thesis prepared by Marc-Olivier Brault during spring 2012 for the fulfillment of his MSc degree at McGill University. We are indebted to Jaime Palter for her helpful comments on the thesis manuscript, and to Michael Havas for technical assistance. Special thanks to Eric Galbraith for helpful tips in finding the cause of the cold anomaly in the Weddell Sea. The support of a Natural Sciences and Engineering Research Council (NSERC) Discovery Grant awarded to LAM, and a research scholarship awarded to M.-O. Brault by the Global Environmental and Climate Change Centre (GEC3) for this work are greatly appreciated.

Edited by: M. Claussen

\section{References}

Alroy, J.: A multispecies overkill simulation of the end-Pleistocene megafaunal mass extinction. Science, 292, 1893-1896, 2001.

Arora, V. K. and Montenegro, A.: Small temperature benefits provided by realistic afforestation efforts, Nat. Geosci., 4, 514-518, 2011.

Bala, G., Caldeira, K., Wickett, M., Phillips, T. J., Lobell, D. B., Delire, C., and Mirin, A.: Combined climate and carbon-cycle effects of large-scale deforestation, Proc. Natl. Acad. Sci. USA, 104, 6550-6555, 2007.

Barnosky, A. D., Koch, P. L., Feranec, R. S., Wing, S. L., and Shabel, A. B.: Assessing the causes of late Pleistocene extinctions on the continents, Science, 306, 70-75, 2004.
Bathiany, S., Claussen, M., Brovkin, V., Raddatz, T., and Gayler, V.: Combined biogeophysical and biogeochemical effects of largescale forest cover changes in the MPI earth system model, Biogeosciences, 7, 1383-1399, doi:10.5194/bg-7-1383-2010, 2010.

Betts, R. A.: Offset of the potential carbon sink from boreal forestation by decreases in surface albedo, Nature, 408, 187-190, 2000.

Bitz, C. M., Holland, M. M., Weaver, A. J., and Eby, M.: Simulating the ice-thickness distribution in a coupled climate model, J. Geophys. Res., 106, 2441-2463, 2001.

Bonan, G. B., Pollard, D., and Thompson, S. L.: Effects of boreal forest vegetation on global climate, Nature, 359, 716-718, 1992.

Bonan, G. B., Chapin III, F. S., and Thompson, S. L.: Boreal forests and tundra ecosystems as components of the climate system, Clim. Change, 29, 145-167, 1995.

Brovkin, V., Levis, S., Loutre, M.-F., Crucifix, M., Claussen, M., Ganopolski, A., Kubatzki, C., and Petoukhov, V.: Stability analysis of the climate-vegetation system in the northern high latitudes, Clim. Change, 57, 119-138, 2003.

Brovkin, V., Raddatz, T., Reick, C. H., Claussen, M., and Gayler, V.: Global biogeophysical interactions between forest and climate, Geophys. Res. Lett., 36, L07405, doi:10.1029/2009GL037543, 2009.

Chalita, S. and Le Treut, H.: The albedo of temperate and boreal forest and the Northern Hemisphere climate: a sensitivity experiment using the LMD GCM, Clim. Dynam., 10, 231-240, 1994.

Claussen, M., Brovkin, V., and Ganopolski, A.: Biogeophysical versus biogeochemical feedbacks of large-scale land-cover change, Geophys. Res. Lett., 28, 1011-1014, 2001.

Cox, P.: Description of the "TRIFFID" Dynamic Global Vegetation Model, Met Office, Hadley Centre technical note 24, 2001.

Cox, P. M., Betts, R. A., Bunton, C. B., Essery, R. L., Rowntree, P. R., and Smith, J.: The impact of new land surface physics on the GCM simulation of climate and climate sensitivity, Clim. Dynam., 15, 183-203, 1999.

Crucifix, M., Betts, R. A., and Hewitt, C. D.: Pre-industrialpotential and Last Glacial Maximum global vegetation simulated with a coupled climate-biosphere model: Diagnosis of bioclimatic relationships, Global Planet. Change, 45, 295-312, 2005.

Davin, E. L. and de Noblet-Ducoudré, N.: Climatic impact of global-scale deforestation: radiative versus nonradiative processes, J. Climate, 23, 97-112, 2010.

De Deyn, G. B., Cornelissen, J. H., and Bardgett, R. D.: Plant functional traits and soil carbon sequestration in contrasting biomes, Ecol. Lett., 11, 516-531, 2008.

Doughty, C. E., Wolf, A., and Field, C. B.: Biophysical feedbacks between the Pleistocene megafauna extinction and climate: The first human-induced global warming?, Geophys. Res. Lett., 37, L15703, doi:10.1029/2010GL043985, 2010.

Douville, H. and Royer, J.-F.: Influence of the temperate and boreal forests on the Northern Hemisphere climate in the Météo-France climate model, Clim. Dynam., 13, 57-74, 1997.

Eby, M., Zickfeld, K., Montenegro, A., Archer, D., Meissner, K. J., and Weaver, A. J.: Lifetime of anthropogenic climate change: millenial time scales of potential $\mathrm{CO}_{2}$ and surface temperature perturbations, J. Climate, 22, 2501-2511, 2009.

Fanning, A. F. and Weaver, A. J.: An atmospheric energy-moisture balance model: climatology, interpentadal climate change, and coupling to an ocean general circulation model, J. Geophys. Res., 128, 15111-15128, 1996. 
Foley, J. A., Prentice, I. C., Ramankutty, N., Levis, S., Pollard, D., Sitch, S., and Haxeltine, A.: An integrated biosphere model of land surface processes, terrestrial carbon balance, and vegetation dynamics, Global Biogeochem. Cy., 10, 603-628, 1996.

Foley, J. A., Costa, M. H., Delire, C., Ramankutty, N., and Snyder, P.: Green surprise? How terrestrial ecosystems could affect earth's climate, Front. Ecol. Environ., 1, 38-44, 2003.

Fraedrich, K., Jansen, H., Kirk, E., and Lunkeit, F.: The Planet Simulator: Green planet and desert world, Meteorol. Z., 14, 305-314, 2005.

Gibbard, S., Caldeira, K., Bala, G., Phillips, T. J., and Wickett, M.: Climate effects of global land cover change, Geophys. Res. Lett., 32, L23705, doi:10.1029/2005GL024550, 2005.

Gill, J. L., Williams, J. W., Jackson, S. T., Lininger, K. B., and Robinson, G. S.: Pleistocene megafaunal collapse, novel plant communities, and enhanced fire regimes in North America, Science, 326, 1100-1103, 2009.

Grayson, D. K. and Meltzer, D. J.: A requiem for North American overkill, J. Archaeol. Sci., 30, 585-593, 2003.

Guthrie, R. D.: New carbon dates like climatic change with human colonization and Pleistocene extinctions, Nature, 441, 207-209, 2006.

Heck, P., Lüthi, D., Wernli, H., and Schär, C.: Climate impacts of European-scale anthropogenic vegetation changes: A sensitivity study using a regional climate model, J. Geophys. Res., 106, 7817-7835, 2001.

Kabat, P., Claussen, M., Dirmeyer, P. A., Gash, J. H. C., de Guenni, L. B., Meybeck, M., Vörösmarty, C. J., Hutjes, R. W. A., and Lütkemeier, S.: Vegetation, water, humans and the climate: A new perspective on an interactive system, in: Global Change: The IGBP Series, Berlin, Springer, p. 566, 2004.

Koch, P. L. and Barnosky, A. D.: Late Quaternary Extinctions: state of the debate, Annu. Rev. Ecol. Evol. Syst., 37, 215-250, 2006.

Martin, P. S.: Twilight of the Mammoths: Ice Age Extinctions and the Rewilding of America, Berkely, CA, Univ. of California Press, 2005.

Matthews, H. D., Weaver, A. J., Meissner, K. J., Gillett, N. P., and Eby, M.: Natural and anthropogenic climate change: incorporating historical land cover change, vegetation dynamics and the global carbon cycle, Clim. Dynam., 22, 461-479, 2004.

Matthews, H. D., Weaver, A. J., and Meissner, K. J.: Terrestrial carbon cycle dynamics under recent and future climate change, J. Climate, 18, 1609-1628, 2005.

Meissner, K. J., Weaver, A. J., Matthews, H. D., and Cox, P. M.: The role of land surface dynamics in glacial inception: a study with the UVic Earth System Model, Clim. Dynam., 21, 515-537, 2003.

Notaro, M. and Liu, Z.: Statistical and dynamical assessment of vegetation feedbacks on climate over the boreal forest, Clim. Dynam., 31, 691-712, 2008.

Otterman, J., Chou, M.-D., and Arking, A.: Effects of nontropical forest cover on climate, J. Clim. Appl. Meteorol., 23, 762-767, 1984.
Owen-Smith, N.: Pleistocene extinctions: the pivotal role of megaherbivores, Paleobiol., 13, 351-362, 1987.

Pacanowski, R. C.: MOM 2 documentation, user's guide and reference manual, Princeton, GFDL Ocean Group Technical Report, NOAA, GFDL, 232 pp., 1995.

Peltier, W. R.: Ice age paleotopography, Science, 265, 195-201, 1994.

Petit, J. R., Jouzel, J., Raynaud, D., Barkov, N. I., Barnola, J.-M., Basile, I., Bender, M., Chappellaz, J., Davis, M., Delaygue, G., Delmotte, M., Kotlyakov, V. M., Legrand, M., Lipenkov, V. Y., Lorius, C., Pépin, L., Ritz, C., Saltzman, E., and Stievenard, M.: Climate and atmospheric history of the past 420,000 years from the Vostok ice core, Antarctica, Nature, 399, 429-436, 1999.

Prentice, I. C., Sykes, M. T., and Cramer, W.: The possible dynamic response of northern forests to global warming, Glob. Ecol. Biogeogr. Lett., 1, 129-135, 1991.

Prescott, G. W., Williams, D. R., Balmford, A., Green, R. E., and Manica, A.: Quantitative global analysis of the role of climate and people in explaining late Quaternary megafaunal extinctions, Proc. Natl. Acad. Sci. USA, 109, 4527-4531, 2012.

Schmittner, A., Oschlies, A., Matthews, H. D., and Galbraith, E. D.: Future changes in climate, ocean circulation, ecosystems, and biogeochemical cycling simulated for a business-as-usual $\mathrm{CO}_{2}$ emission scenario until year 4000 Ad, Global Biogeochem. Cy., 22, GB1013, doi:10.1029/2007GB002953, 2008.

Simmons, C. T., Mysak, L. A., and Matthews, H. D.: Investigation of carbon dynamics since the Last Glacial Maximum with a model of intermediate complexity. Poster presented at the annual meeting of the American Geophysical Union, San Francisco, USA, 2012.

Snyder, P. K., Delire, C., and Foley, J. A.: Evaluating the influence of different vegetation biomes on the global climate, Clim. Dynam., 23, 279-302, 2004.

Swann, A. L., Fung, I. Y., Levis, S., Bonan, G. B., and Doney, S. C.: Changes in arctic vegetation amplify high-latitude warming through the greenhouse effect, Proc. Nat. Acad. Sci. USA, 107, 1295-1300, 2010.

Thomas, G. and Rowntree, P. R.: The boreal forests and climate, Q. J. R. Meteorol. Soc., 118, 469-497, 1992.

Weaver, A. J., Eby, M., Wiebe, E. C., Bitz, C. M., Duffy, P. B., Ewen, T. L., Fanning, A. F., Holland, M. M., MacFadyen, A., Matthews, H. D., Meissner, K. J., Saenko, O., Schmittner, A., Wang, H., and Yoshimori, M.: The UVic Earth System Climate Model: model description, climatology, and applications to past, present and future climates, Atmos. Ocean, 39, 361-428, 2001.

Wroe, S., Field, J., Fullagar, R., and Jermin, L. S.: Megafaunal extinction in the late Quaternary and the global overkill hypothesis, in: Alcheringa: An Australasian Journal of Palaeontology, London, Taylor \& Francis, 291-331, 2004.

Zimov, S. A., Zimov, N. S., Zimova, A. E., Zimova, G. M., Chuprynin, V. I., and Chapin III, F. S.: Carbon storage in permafrost and soils of the mammoth tundra-steppe biome: Role in the global carbon budget, Geophys. Res. Lett., 36, L02502, doi:10.1029/2008GL036332, 2009. 